\title{
COMO TRANSMITIR AOS JOVENS INVESTIGADORES A HISTÓRIA RECENTE DA NOSSA CIÊNCIA?
}

\author{
SUZANNE DAVEAU ${ }^{1}$
}

\begin{abstract}
Resumo - Um bom conhecimento da evolução dos temas e métodos de investigação em Geografia, a partir da Segunda Guerra Mundial, facilitaria o eficaz desenvolvimento da nossa ciência. O que implica a transmissão intergeneracional deste tipo de saber. Apresentam-se em exemplos vários estudos recentes, relativos às escolas de Geografia portuguesas e francesas e a alguns dos temas de investigação que desenvolveram.
\end{abstract}

Palavras-chave: Metodologia, história da Geografia, gerações.

\begin{abstract}
HOW TO CONVEY THE RECENT HISTORY OF OUR SCIENCE TO YOUNG RESEARCHERS? A good knowledge of the development of themes and research methods, used in geography since the Second World War, would facilitate the effective development of our science. This implies the transmission of this kind of knowledge between generations. We present several examples of recent studies pertaining to Portuguese and French schools of Geography and of some of the research topics they have developed.
\end{abstract}

Keywords: Methodology, history of Geography, generations.

Résumé - COMMENT FAIRE CONNAÎTRE AUX JEUNES CHERCHEURS L'HISTOIRE RÉCENTE DE NOTRE SCIENCE ? Une bonne connaissance de l'évolution des thèmes et méthodes de recherche en Géographie, depuis la Seconde Guerre Mondiale, permettrait de lui assurer un développement plus efficace. Ce qui implique la transmission de ce type de savoir d'une génération de chercheurs à l'autre. On présente quelques études récentes, relatives aux écoles portugaises et françaises de Géographie et à quelques-uns des thèmes de recherche qu'elles ont développés.

Mots-clés: Méthodologie, histoire de la Géographie, générations.

Num centro de investigação em plena actividade como é caso do Centro de Estudos Geográficos de Lisboa, a tendência natural dos mais jovens é de olharem para o futuro e experimentarem ideias e técnicas novas, em vez de seguir as rotinas de trabalho praticadas pela geração anterior. Muitos deles têm assim a tentação de "matar o pai", para seguirem com

Recebido: Maio 2011. Aceite: Dezembro 2011.

1 Investigadora do Centro de Estudos Geográficos-UL. E-mail: sdaveau@clix.pt 
maior liberdade caminhos novos. Mas se esta atitude é um factor útil de actualização e de progresso, ela não tira aos investigadores mais velhos a obrigação complementar de transmitir à nova geração uma visão clara do que foi a prática científica no período anterior. Para se construir solidamente o futuro, este tem de assentar em alicerces não apenas robustos, mas claramente conhecidos.

\section{O QUE SABEMOS DA HISTÓRIA RECENTE DA NOSSA CIÊNCIA?}

A Geografia, tal como a entendemos hoje, continua sendo uma ciência jovem, em plena evolução. Há pouco mais de um século, quando se organizaram os primeiros Congressos Internacionais de Geografia (Amaral, 1968), conseguiam-se reunir quase todos os geógrafos então activos. O fundador da Geografia universitária em Lisboa, Silva Telles (1860-1930), participou em 1908 no Congresso de Genebra (Pimenta, 2004: I) e Orlando Ribeiro (1911-1987) no de Amesterdão em 1938 (Ribeiro, 2003: 88). O Congresso seguinte, protelado pelo deflagrar da Segunda Guerra Mundial, realizou-se em Lisboa, em 1949, e foi o exemplo brilhante, mas terminal, de um tipo de reuniões internacionais que permitiam a muitos dos participantes estabelecer ligações científicas pessoais, sólidas e duráveis. Na altura, "a geografia interessava [ainda] pouca gente, nos poucos países em que era praticada." (Dresch, 1979: 7).

Quanto a mim, já faço parte da geração seguinte, a do imediato pós-guerra, geração que conheceu uma brusca multiplicação em todo o Mundo dos centros de ensino e de investigação em Geografia. Nos anos em que me formei e comecei a ensinar, as relações profissionais de escala humana conseguiam ainda manter-se gerais e vivas no quadro de cada país, em boa parte graças às excursões ditas interuniversitárias, mas o mesmo já não era possível à escala internacional. Os grandes Congressos Internacionais tinham já perdido boa parte da sua eficácia e eram, pouco a pouco, substituídos por Colóquios mais especializados.

A nossa ciência estava, com efeito, a sofrer na altura uma mutação profunda, dividindose por especializações temáticas, que a linguagem técnica forjada por cada uma ia tornar rapidamente estanques, por ser de difícil compreensão pelos colegas diversamente orientados. Novas ideologias socioeconómicas estavam proliferando, na mesma altura, cada uma convencida que ia reunir em breve, sob a própria bandeira, todos os geógrafos válidos, pela absorção ou desaparição das modalidades científicas julgadas perversas ou ultrapassadas. Foi assim que surgiram, paralela ou sucessivamente, a efémera Nova Geografia e as inúmeras Geografias ditas quantitativa ou teórica, marxista, social ou cultural, aplicada ou voluntária, física, ambiental ou climática, colonial, tropical ou zonal, humana, urbana, rural, de fluxos ou de "géneros", etc.

Na mesma altura, estava a constituir-se e a alargar-se muito o público potencialmente interessado nas publicações geográficas. Isto, por causa do preço cada vez mais acessível e da crescente comodidade dos transportes terrestres e aéreos, que permitiam a muita gente ampliar o seu conhecimento do Mundo, mesmo quando era apenas num plano turístico bastante superficial. Mas a linguagem abstrusa, cada vez mais usada pelos membros das múltiplas "seitas" em que se tinha fragmentado a sociedade dos geógrafos, tinha tornado, e continua a tornar, a maior parte das suas publicações praticamente ininteligíveis e, logo, pouco apelativas para o grande público. A não difusão actual dos nossos trabalhos, entre os numerosos leitores que estariam, a priori, interessados nos resultados da recente e activa investigação geográfica, constitui um facto deveras aflitivo, fácil de comprovar. Basta percorrer qualquer grande livraria urbana, para notar logo que, enquanto a secção de História é larga- 
mente provida e frequentada, bem como a de Turismo e Viagens, os raros livros reunidos sob a rubrica de Geografia são difíceis de encontrar, relegados como estão para poucas e inacessíveis estantes. O grande e rápido sucesso, que encontraram os quatro belos volumes da Geografia de Portugal dirigida por Carlos Alberto Medeiros, publicados em 2005-06 pelo Círculo de Leitores, mostra bem quão necessária era a difusão de uma obra sólida e actualizada sobre a Geografia do país, mas a não reedição de uma obra tão rapidamente esgotada testemunha igualmente da dificuldade que os geógrafos encontram presentemente em serem "ouvidos" pelo grande público.

Para que a nossa ciência volte a ter a larga difusão e a influência social que merece, parece-me indispensável que os próprios geógrafos tenham uma clara percepção do que foi a complexa fase do imediato pós-Segunda Guerra Mundial, quando a Geografia conheceu um desenvolvimento e uma diversificação espectaculares, mas sem ter sabido manter ou desenvolver o amplo papel de formação e de aplicação cidadã, que com razão ambicionava. Na verdade, nada até hoje substituiu, para o público português não especializado, as duas obras de ampla divulgação que foram, tanto o Atlas de Portugal (1940, com reedição em 1958) como a Geografia de Portugal (1941), elaborados por Amorim Girão. A nossa ciência progrediu muito entretanto, mas ela encontra-se hoje numa grave situação de crise e de desorganização interna, acrescentada de medíocres relações externas, tanto interdisciplinares como sociais.

Ora, os geógrafos que viveram directamente a recente fase de crescimento brilhante e desordenado da sua ciência, ou já morreram ou vão desaparecendo, uns a seguir aos outros. É portanto urgente recolher os poucos espólios científicos que não foram ainda destruídos, bem como o depoimento dos raros sobreviventes e testemunhos. E seria também urgente acertar a metodologia mais bem adaptada ao estudo daqueles diversos tipos de documentos.

\section{ALGUNS ESTUDOS SOBRE A HISTÓRIA RECENTE DA GEOGRAFIA}

Por ter pessoalmente viva consciência destas urgências, queria agora, através de alguns exemplos que conheço melhor, chamar a atenção sobre o que se está - ou não se está - praticando, e sobre as pistas de investigação que julgo mais útil desenvolver. Com efeito, tentar escrever a história recente de uma ciência levanta problemas epistemológicos particulares. Além da publicação ou reedição das obras científicas mais importantes, este tipo de investigação pode, e deve, apoiar-se também no testemunho directo dos próprios actores e dos seus mais próximos alunos e colaboradores. Ora, os modos de utilização destes tipos de documentos têm exigências particulares.

Poucos são os geógrafos que escreveram as suas memórias ou que prepararam colectâneas dos seus estudos mais importantes. Foi o caso, em Portugal, de Orlando Ribeiro (1960, 1986, 1989-95, 2003), mas nem Amorim Girão nem Fernandes Martins o fizeram. Em ramos próximos da Geografia, preciosas biografias científicas foram devidas a discípulos dedicados, como a de Viegas Guerreiro (Ferreira, 2006), de Leite de Vasconcelos (Costa et al., 2008) e de Paul Choffat (Rocha, 2008). A recolha da correspondência fornece outro tipo de documentos, muito preciosos por estarem, em geral, exactamente situados no tempo e não interpretados (Daveau, 2007; Alegria et al., 2011).

Outra forma de depoimento directo, cada vez mais usada, é o registo de uma entrevista conduzida, em geral, por um colega mais novo. A Internet assegura hoje ampla e rápida difusão a este tipo de recolha. Veja-se, como exemplo, o Entretien avec Paul Pélissier, recolhido 
por J. M. Théodat (2007). A transcrição do diálogo informal entre os dois geógrafos, de origens e gerações diferentes, traz uma luz viva sobre a rica experiência do grande especialista da Geografia tropical que acaba de desaparecer, e permite matizar o sentido de conceitos aparentemente claros, como os de "colonização" ou de "colonialismo", que são de sentidos na realidade tão polivalentes, que podem levar a infelizes contra-sensos históricos.

Este assunto é de particular significado para se conseguir uma justa apreciação do importante ramo da Geografia portuguesa que foi dedicado ao Ultramar, ramo que ficou quase totalmente negligenciado a seguir aos últimos livros que Orlando Ribeiro lhe dedicou, em 1975 e 1981, mas que voltou recentemente a ser proficuamente investigado (Pimenta, 2010; Isabel Medeiros, 2010). Já se podem ler também com proveito tanto o estudo recente de M. Bandeira Jerónimo (2009) como as actas do colóquio Tropicalités en Géographie (Velasco-Graciet, 2008) e, em particular, a conclusão de Paul Pélissier. Foi ainda sobre este mesmo tema, que voltou a ser considerado de actualidade, que a União Geográfica Internacional preparou, em Junho de 2011, um Simpósio Internacional, na Praia, em Cabo Verde, sobre História da Geografia e Colonialismo.

As publicações que associam, a uma entrevista ou a um depoimento do homenageado, uma selecção das suas próprias obras, são de interesse particular, maior que muitos dos tradicionais Livros de Homenagem, que agrupam, em geral, temas demasiado dispersos. Relativamente aos colegas franceses mais ou menos directamente ligados a Portugal (Claval, 1998), já se citou a colectânea de obras de Jean Dresch (1979), promovida por Yves Lacoste. Outro excelente exemplo, consagrado a Jean Demangeot, foi recentemente devido a C. Daudel (2008). A primeira parte deste livro transcreve uma série de entrevistas, consagradas a aspectos da vida profissional do geógrafo e aos temas científicos mais do seu agrado, enquanto a segunda parte reúne uma antologia de 39 textos. Enquadrados por cuidadosos índices, estes extractos facilitam um acesso equilibrado a uma obra cientificamente rica, diversificada e sempre escrita numa linguagem límpida, acessível a qualquer curioso.

As publicações que Claude Bataillon tem dedicado à história da Geografia francesa do imediato pós-guerra merecem também ser aqui destacadas. Desde há muito interessado pelo assunto, este "geógrafo francês na América latina" (2008), elaborou uma metodologia original para dar conta da evolução recente da nossa disciplina. Em vez de proceder ao estudo específico de determinada personalidade, ele agrupou os seus colegas por gerações e, em vez de lhes deixar completamente a palavra ou de anexá-la, procurou um subtil equilíbrio entre o enunciado da sua própria visão e os depoimentos dos interessados.

Em 2006, ele tinha já difundido, na revista Cybergeo, acessível na Internet, um artigo intitulado "Six géographes en quête d'engagement: du communisme à l'aménagement du territoire. Essai sur une génération". Tratava-se então de R. Guglielmo, B. Kayser, Y. Lacoste, A. Prenant, M. Rochefort e R. Dugrand, todos nascidos entre 1923 e 1927, e com percursos políticos e profissionais mais ou menos comparáveis. O estudo estava baseado tanto em recordações pessoais como em entrevistas e conversas com aqueles colegas.

Claude Bataillon publicou em 2009 outro estudo, mais desenvolvido e dedicado a seis geógrafos franceses, da geração imediatamente posterior: R. Brunet, P. Claval, O. Dollfus, F. Durand-Dastès, A. Frémont e F. Verger. O livro (Géographes, Génération 1930) comporta uma primeira parte, chamada "Récit", que apresenta a visão do autor sobre o desenrolar da carreira dos seus colegas, frisando os paralelismos e as convergências. Numa segunda parte, intitulada "Autobibliographies et choix de textes personnels", ele deixa a palavra aos colegas retratados, para estes apresentarem os aspectos mais salientes da sua personalidade e da sua obra, e proporem ao leitor alguns textos escolhidos. Conseguiu assim um convincente e ele- 
gante equilíbrio entre a própria interpretação e o que seria uma sucessão um pouco seca de notícias pessoais. Resta saber se a noção de "geração" será aqui completamente pertinente e também se a escolha do autor a exemplifica convenientemente, ou corresponde sobretudo ao grupo dos colegas que lhe são mais próximos. Mas, de facto, a selecção feita parece-me reflectir adequadamente o ambiente universitário francês da época, em que os melhores alunos das diversas universidades confluíam na capital, para coroar aí os seus anos de formação com o almejado título de "agrégé".

Multiplicaram-se recentemente os Colóquios, destinados a explorar o passado mais próximo da nossa disciplina, pelo entrecruzar de depoimentos dos sobreviventes, de homenagens aos desaparecidos e de novas investigações sobre os temas então desenvolvidos. Foi o caso do encontro internacional decorrido em São Paulo (Brasil) em Dezembro de 2008 e apresentado em Geografia: Tradições e Perspectivas. A Presença de Pierre Monbeig (Lemos e Galvani, 2009). Aquele geógrafo francês ensinou em São Paulo de 1935 a 1956, tendo consagrado a tese à "frente pioneira" cafezeira paulista e formado grande parte da primeira geração de geógrafos brasileiros.

Em Outubro de 2009, ocorreu em Paris um primeiro encontro, dedicado a Géographes et Géographie Française à l'Épreuve de la Seconde Guerre Mondiale, organizado por M. C. Robic e J. L. Tissier, e promovido pela secção "Épistémologie et Histoire de la Géographie" do Centre National de la Recherche Scientifique (C.N.R.S). A primeira parte, "Écrire et publier sous surveillance", tratou da actividade científica em França, então constrangida por uma estreita censura; a segunda parte foi consagrada à difícil manutenção das relações científicas internacionais: uma comunicação foi dedicada a Jean Gottmann e ao núcleo dos Europeus então exilados em Nova Iorque, duas outras às relações da Geografia francesa com Espanha, realçando o papel de Pierre Deffontaines e de Solé Sabaris, enquanto eu própria mostrava o papel complementar e amigável que O. Ribeiro, P. Birot e E. de Martonne tiveram, no arrancar do importante surto científico que Portugal conheceu durante a guerra. Novo encontro decorreu em Paris, em 9 de Novembro de 2010, prolongando o mesmo tipo de investigação.

A modo de conclusão provisória, queria realçar quão urgente me parece a recolha e a preservação da documentação sobrevivente sobre o período em que as actuais escolas de Geografia portuguesas se constituíram (Daveau, 2008), quer a documentação escrita quer os depoimentos orais. E quão necessário também seria experimentar e definir, desde já, a metodologia mais adaptada, capaz de extrair daqueles dados um conhecimento equilibrado, onde alicerçar de modo seguro actuais e futuras investigações.

\section{BIBLIOGRAFIA}

Alegria M F, Daveau S, Garcia J C (2011) (org.) Leite de Vasconcelos e Orlando Ribeiro. Encontros epistolares (1931-1941). Imprensa Nacional - Casa da Moeda, Lisboa.

Amaral I (1968) A Geografia através dos seus Congressos Internacionais. Finisterra - Revista Portuguesa de Geografia, Lisboa, III(5): 84-101.

Bataillon C (2009) Géographes, Génération 1930. Presses Universitaires de Rennes, Rennes.
Bataillon C (2008) Un Géographe français en Amérique Latine, Quarante années de souvenirs et de Réflexions. La Documentation française, Paris.

Bataillon C (2006) Six géographes en quête d'engagement: du communisme à l'aménagement du territoire. Essai sur une génération. Cybergeo, 341: 1-15.

Claval P (1998) Histoire de la Géographie française de 1870 à nos jours. Nathan, Paris. 
Costa L C, Cardoso J L, Martins A C (2008) José Leite de Vasconcelos, Fotobiografia. Museu Nacional de Arte Antiga, Lisboa.

Daudel C (2008) Jean Demangeot. Géographe de terrain. L'Harmattan, Paris.

Daveau S (2008) O espólio científico do Professor Orlando Ribeiro. Finisterra - Revista Portuguesa de Geografia, 85: 123-138.

Daveau S (2007) La Géographie, ça peut survivre à la guerre. Correspondance entre Jean Gottmann et Orlando Ribeiro. Finisterra - Revista Portuguesa de Geografia, Lisboa, XLII(83): 5-21.

Dresch J (1979) Un Géographe au déclin des empires. Hérodote. Maspero, Paris.

Ferreira F M (2006) Manuel Viegas Guerreiro, Fotobiografia. Fundação Manuel Viegas Guerreiro, Loulé.

Jerónimo M B (2009) Livros brancos, almas negras. A "Missão Civilizadora" do colonialismo português, c. 1870-1930. Imprensa de Ciências Sociais, Lisboa.

Lemos A I G, Galvani E (2009) (org.) Geografia, tradições e perspectivas. A presença de Pierre Monbeig. Departamento de Geografia, Universidade de São Paulo, São Paulo.

Medeiros C A (2005-06) (org.) Geografia de Portugal. Círculo de Leitores, Lisboa, 4 volumes.

Medeiros I (2010) Serão explicáveis os conflitos violentos em África? Notas de leitura. Finisterra - Revista Portuguesa de Geografia, Lisboa, XLV(89): 181-204.
Pimenta J R (2010) Portuguese colonial geographical tradition (1926-1974). Africana Studia, 14: 315-322.

Pimenta J R (2004) Introdução. In Obras de Silva Telles. A Ciência Geográfica, Associação Portuguesa de Geógrafos, Lisboa.

Ribeiro O (2003) Memórias de um Geógrafo. Edições João Sá da Costa, Lisboa.

Ribeiro O (1989-95) Opúsculos Geográficos. Fundação Calouste Gulbenkian, Lisboa, 6 volumes.

Ribeiro O (1986) Cinquenta anos de vida científica e universitária. Revista da Faculdade de Letras de Lisboa, $5^{\text {a }}$ série, 6: 11-20.

Ribeiro O (1981) A Colonização de Angola e o seu fracasso. Imprensa Nacional - Casa da Moeda, Lisboa.

Ribeiro O (1975) Destinos do Ultramar. Livros Horizonte, Lisboa.

Ribeiro O (1970) Meio século de estudos geográficos. In Ensaios de Geografia Humana e Regional, Livraria Sá da Costa, Lisboa.

Rocha R B, et al. (2008) (ed.) Paul Choffat na Geologia portuguesa. Universidade Nova de Lisboa, INETI, Lisboa, 2 volumes.

Théodat J M (2007) Entretien avec Paul Pélissier, 6/2/2007. EchoGéo, 1: 1-15 http://echogeo. revues.org//index $1660 . \mathrm{htm}$

Velasco-Graciet H (2008) (dir.) Les tropiques des Géographes. Maison des Sciences de l'Homme d'Aquitaine, Pessac. 